University of Nebraska - Lincoln

DigitalCommons@University of Nebraska - Lincoln

$12-1998$

\title{
Effects of Food Deprivation, Age, Time of Day, and Gamma Irradiation on Attraction of Mexican Fruit Flies (Diptera: Tephritidae) to Two Synthetic Lures in a Wind Tunnel
}

David C. Robacker

Crop Quality and Fruit Insects Research, USDA-ARS, 2301 S. International Boulevard, Weslaco, TX 78596

Follow this and additional works at: https://digitalcommons.unl.edu/entomologyother

Part of the Entomology Commons

Robacker, David C., "Effects of Food Deprivation, Age, Time of Day, and Gamma Irradiation on Attraction of Mexican Fruit Flies (Diptera: Tephritidae) to Two Synthetic Lures in a Wind Tunnel" (1998). Entomology Papers from Other Sources. 82.

https://digitalcommons.unl.edu/entomologyother/82

This Article is brought to you for free and open access by the Entomology Collections, Miscellaneous at DigitalCommons@University of Nebraska - Lincoln. It has been accepted for inclusion in Entomology Papers from Other Sources by an authorized administrator of DigitalCommons@University of Nebraska - Lincoln. 
Physiological and Chemical Ecology

\title{
Effects of Food Deprivation, Age, Time of Day, and Gamma Irradiation on Attraction of Mexican Fruit Flies (Diptera: Tephritidae) to Two Synthetic Lures in a Wind Tunnel
}

\author{
DAVID C. ROBACKER
}

Crop Quality and Fruit Insects Research, USDA-ARS, 2301 S. International Boulevard, Weslaco, TX 78596

Environ. Entomol. 27(6): 1303-1:309 (1998)

ABSTRACT The physiological condition of Mexican fruit flies, Anastrepha ludens (Loew), affected their attraction to 2 similar but qualitatively different synthetic lures in wind-tunnel bioassays. The 2 lures were BioLure (ammonium acetate and putrescine) and AMPu (ammonium carbonate, methylamine $\mathrm{HCl}$, and putrescine). Effects of food deprivation on attraction to the lures were smaller than the effects of sex, time of day, and irradiation. Sugar-fed, protein-starved flies were attracted more strongly than other hunger-status groups to the lures. Sugar-starved, protein-starved females were less responsive than other groups of females to AMPu. Protein-starved males were more responsive than protein-fed males to BioLure. Females were nearly twice as responsive as males to the lures. Both lures were more attractive to females early and late in the photophase and more attractive to males during midphotophase. Gamma irradiation of flies greatly reduced their attraction to both lures. Fly age from 6 to $17 \mathrm{~d}$ after eclosion had little effect on attraction to the lures. AMPu was more than twice as attractive as BioLure summed over all wind-tunnel experiments. A field test using BioLure and AMPu on sticky traps confirmed the greater attractiveness of AMPu to laboratorycolony flies.

KEY WORDS Anastrepha ludens, attractants, lures, ammonia, ammonium acetate, putrescine

Two SYNTHETIC CHEMICAL blends developed recently as trap lures for fruit flies have been reported as attractive to the Mexican fruit fly, Anastrepha ludens (Loew). The lst is AMPu, a mixture of ammonium bicarbonate or ammonium carbonate, methylamine $\mathrm{HCl}$, and putrescine, developed specifically for the Mexican fruit fly (Robacker and Warfield 1993). BioLure, a commercial formulation of ammonium acetate and putrescine, was developed as an attractant for the Mediterranean fruit fly, Ceratitis capitata (Wiedemann) but also attracts the Mexican fruit fly (Heath et al. 1995).

During the past decade, considerable progress has been made in determining how the physiological state of the Mexican fruit fly affects attraction of the flies to pheromones, host-fruit odor, and bacterial odor. This work has shown that each type of semiochemical is most attractive to flies of a particular physiological state (Robacker and Garcia 1993). An important lesson has been that, under some physiological conditions, adding an attractive chemical to a highly attractive set of chemicals may result in a combination that is less attractive than the original set. This was observed when combinations of acetic acid with $\mathrm{AMPu}$ were less attractive than AMPu alone, except to flies in 1 food-deprivation state out of several that were tested (Robacker et al. 1996).

This article reports the results of research only. Mention of proprietary product does not constitute an endorsement or a recommendation by USDA for its use
The effect of acetic acid on attractiveness of AMPu has important implications concerning the use of $\mathrm{AMPu}$ and BioLure to monitor field populations of Mexican fruit flies. Both lures rely on ammonia and putrescine as attractive principals, but they differ in that $\mathrm{AMPu}$ also emits methylamine whereas BioLure emits acetic acid. These subtle differences in active components could effect differential attractiveness of the lures, depending on local environmental conditions and physiological states of flies in the target populations. In fact, preliminary field testing of AMPu and BioLure in Texas and Guatemala has indicated that differential attractiveness of the 2 lures may occur.

The purpose of this research was to determine how changes in physiological state induced by sugar and protein deprivation, aging, circadian rhythm, and gamma irradiation of flies before eclosion affect attraction of Mexican fruit flies to AMPu and BioLure. This information may be useful to trapping-program managers as a guide in selection of lures for specific times and localities in accordance with food availability, age structure of fly populations, and proportion of irradiated flies present in orchards.

\section{Materials and Methods}

Insects and Laboratory Conditions. Flies were from a culture that originated from yellow chapote fruit, a native host of the Mexican fruit fly, collected in Nuevo Leon, Mexico, in 1987. The culture has been main- 
tained on laboratory diet since establishment $(\approx 100$ generations). Adult feeding regimes differed according to experiment and are described below. Laboratory conditions for holding flies were $22 \pm 2^{\circ} \mathrm{C}, 50 \pm$ $20 \% \mathrm{RH}$, and photophase from 0630 to 1930 hours provided by fluorescent lights.

Lures. BioLure lures were obtained from Consep (Bend, OR). They consisted of an ammonium acetate packet and a putrescine packet. The 2 packets were taped together with their membrane openings unobstructed and separated from each other for use in the wind tunnel bioassay. BioLure lures were used each day for $5 \mathrm{~d}$ after removal from refrigeration. These lures produce stable emissions of their components for at least $6 \mathrm{wk}$ in the laboratory (R. R. Heath, personal communication). Laboratory tests to measure emissions of BioLure components indicated that the lures emit (at a laboratory temperature $\approx 23^{\circ} \mathrm{C}$ ) $\approx 300 \mu \mathrm{g} / \mathrm{h}$ of ammonia (Heath et al. 1997). Emission of acetic acid is probably $\approx 3-12 \mu \mathrm{g} / \mathrm{h}$. These rates for acetic acid were reported by Heath et al. (1995) for a similar ammonium acetate packet (Consep) that emitted $100-500 \mu \mathrm{g} / \mathrm{h}$ of ammonia. Putrescine emission has not been determined for BioLure.

$\mathrm{AMPu}$ was used in an agar formulation in $1.9-\mathrm{ml}$ polypropylene microcentrifuge tubes (A. Daigger, Wheeling, IL). This AMPu formulation was highly attractive to irradiated Mexican fruit flies in a citrus orchard (Robacker 1995). AMPu/agar tubes were prepared by mixing equal volumes of hot agar solution (Bacto Agar, Difco, Detroit, MI) and aqueous AMPu containing 120,200 , and $20 \mathrm{mg} / \mathrm{ml}$, respectively, of ammonium carbonate (ACS Reagent quality, Aldrich, Milwaukee, WI), methylamine hydrochloride $(99 \%$, Sigma, St. Louis, MO), and putrescine (98\%, Aldrich). Final concentrations in AMPu/agar tubes were 60, 100 , and $10 \mathrm{mg} / \mathrm{ml}$ of the 3 chemicals and $1 \%$ agar in a final volume of $1.7 \mathrm{ml}$. The $\mathrm{pH}$ of the $\mathrm{AMPu} /$ agar formulation was 8.7-8.9. AMPu tubes were capped and stored in a refrigerator. They were used in tests for $1 \mathrm{~d}$ after removal from refrigeration. Lures were discarded after $1 \mathrm{~d}$ because this agar formulation was developed only for short-term delivery of the AMPu components. Previous laboratory tests to measure emissions of AMPu components indicated that these lures emit (at $35^{\circ} \mathrm{C}$ ) $\approx 300 \mu \mathrm{g} / \mathrm{h}$ of ammonia, $40 \mu \mathrm{g} / \mathrm{h}$ of methylamine, $17 \mathrm{ng} / \mathrm{h}$ of putrescine, and $20 \mathrm{ng} / \mathrm{h}$ of 1-pyrroline, a chemical that forms spontaneously in the lures (Robacker and Bartelt 1996).

Wind-Tunnel Bioassay. Most bioassays were conducted in a wind tunnel, a rectangular box $(0.3$ by 0.3 by $1.2 \mathrm{~m}$ ) constructed from Plexiglas. Wind tunnels of similar dimensions have been used successfully for bioassays of fruit fly semiochemicals (Landolt et al. 1992, Epsky et al. 1997). The bioassay method used for this work was modeled after that used by Landolt et al. (1992).

Each end of the wind tunnel was screened to allow airflow. The downwind end contained a baffle system to create a uniform airflow through the chamber. Air was pulled through the chamber at $0.4 \mathrm{~m} / \mathrm{s}$ by an exhaust fan connected to the downwind end. Air leav- ing the chamber was vented from the room by a ceiling exhaust fan. The top of the chamber had 2 circular service openings $(12.8 \mathrm{~cm}$ diameter) with Plexiglas covers, 1 located near each end of the chamber to allow easy access to the chamber interior. A 100-W Soft White light bulb (General Electric, Cleveland, $\mathrm{OH})$ in a reflecting lamp was positioned $17 \mathrm{~cm}$ above the downwind end of the chamber. The purpose of this light was to hold flies nonresponsive to lure odors in the downwind end by positive phototaxis and thus minimize random flying into the upwind end of the chamber. Overhead lighting was provided by 2 banks of 4 fluorescent Cool White lights each (F40CW, General Electric).

Lures (AMPu tubes or BioLure lures) were attached on 1 side of a yellow plastic panel ( 10 by 13 $\mathrm{cm}$ ). These panels previously were evaluated in field experiments with the Mexican fruit fly (Robacker 1992). One panel with 1 lure was suspended from the service opening at the upwind end of the chamber oriented to provide a broad visual stimulus to responding flies downwind and with the lure on the upwind side of the panel away from responding flies. In this configuration the panel was $21 \mathrm{~cm}$ away from the upwind end and nearly in the center of the air stream (midway between top and bottom and the sides).

Flies were introduced $l$ at a time into the downwind end of the chamber in clear plastic vials $(7 \mathrm{by} 3 \mathrm{~cm}$ diameter) placed on top of a beaker on the bottom of the chamber directly below the downwind service opening. In this configuration, the top of the vial (where the fly would emerge) was located in the center of the air stream. Each fly was allowed 5 min to leave the vial (fly or walk off of the vial). Flies that did not leave in 5 min were not included in the data. Once a fly left the vial, the fly was allowed 5 min to fly or walk upwind or contact the panel. Upwind movement was scored if flies passed a point $2 / 3$ of the distance from the release vial to the panel.

Two identical chambers were used for the tests. One chamber was used for AMPu and the other for BioLure for a series of tests (usually $\approx 20$ replications of each experiment); then chambers were washed with soapy water (all test chemicals are water soluble) and the lures were tested in the other chambers for a series. Comparison of data obtained in each chamber for the same lure and fly treatments showed that fly responses were not affected by chamber.

Sugar/Protein Deprivation Experiment. The purpose of this experiment was to determine if hunger for sugar, protein, or both affected attraction of flies to $\mathrm{AMPu}$ and BioLure. Two mixed-sex groups of flies were held until they were $3-8 \mathrm{~d}$ old in separate Plexiglas cages (20.3 cm per side). Each cage had a screened opening $(10 \mathrm{~cm}$ diameter $)$ on the top and a sleeved opening ( $15.3 \mathrm{~cm}$ diameter) on 1 side. One cage was provisioned with sucrose (sugar cubes) and water (sugar-fed, protein-starved). The 2 nd cage was provisioned with sugar cubes, casein hydrolysate (ICN Biomedicals, Irvine, CA), and water (sugar-fed, protein-fed). Subsets of $30-40$ flies were drawn from the 2 cages $2 \mathrm{~d}$ before bioassays to set up 2 additional 
feeding regimes in similar cages. Flies from the sugarfed, protein-starved group were held with water only (sugar-starved, protein-starved). Flies from the sugarfed, protein-fed group were held with casein hydrolysate and water (sugar-starved, protein-fed). Feeding regimes were set up this way because previous experiments showed that sugar deprivation for $3 \mathrm{~d}$ caused high mortality (Robacker and Garcia 1993). Protein deprivation from the time of eclosion caused no significant mortality and resulted in increasing levels of attraction of flies to bacterial odor up to at least $7 \mathrm{~d}$ of deprivation.

Flies were tested individually for attraction to 1 of the 2 lures in the wind-tunnel bioassay at various times during the photophase. Flies were tested at ages 5-10 $\mathrm{d}$ after eclosion. Previous experiments showed that age of Mexican fruit flies between 2 and $20 \mathrm{~d}$ after eclosion had little effect on their attraction to Staphylococcus cultures that emitted many of the same chemicals as AMPu and BioLure including ammonia, methylamine, and acetic acid (Robacker and Garcia 1993, Robacker and Flath 1995). Sixty replications of the experiment were conducted where each replication included 1 test ( $1 \mathrm{fly}$ ) each of the 16 treatments ( 2 sexes $\times 4$ hunger-status treatments $\times 2$ lures) in a randomized complete block design. Forty replications of the wind tunnel bioassay were also conducted with a panel that did not contain a lure to determine if the various hunger-status groups had different propensities to fly upwind and land on the panels.

Irradiation Experiment. The purpose of this experiment was to determine if irradiation of flies affected their attraction to $\mathrm{AMPu}$ and BioLure. Flies were irradiated with $70-84.7 \mathrm{~Gy}\left({ }^{137} \mathrm{Cs}\right.$ source) $1-2 \mathrm{~d}$ before adult eclosion. Mixed-sex groups of 180-200 irradiated flies were put into a Plexiglas holding cage (described above) until testing. Control (not irradiated) flies from the same cohort were held in a 2nd cage. Flies were given constant access to water and sucrose but no protein source was provided. Individual flies were tested in the wind-tunnel bioassay at various ages (6-17 d after eclosion) and at various times of the photophase. Forty replications of the experiment were conducted where each replication included 1 test each of the 8 treatments $(2$ sexes $\times 2$ irradiation/control treatments $\times 2$ lures) in a randomized complete block design.

Citrus Orchard Test. To determine if wind-tunnel results were comparable to results with traps in the field, AMPu and BioLure lures were evaluated in a citrus orchard using irradiated (to comply with quarantine laws) flies. A mixed citrus orchard located near the laboratory in Weslaco, TX, was used. The orchard contained several varieties of orange, lemon, grapefruit, and tangerine trees of varying ages. One row of Ruby Red Grapefruit (Citrus paradisi MacFadyen) and 1 row of Dancy Tangerine (C. reticulata Blanco) were chosen for tests. Three blocks of 3 trees each were used in each row, for a total of 6 blocks in the orchard. Traps were placed on the 1st and 3rd tree in each block, 1 trap containing an AMPu tube and the other containing a BioLure double packet (ammoni- um acetate and putrescine packets taped together). Pherocon AM (No Bait) traps (Trece, Salinas, CA) were used for both lures. Pherocon AM (no bait) traps are yellow cardboard panels ( 14 by $23 \mathrm{~cm}$ ) with a sticky coating. Traps were hung at $1-2 \mathrm{~m}$ height, north of center. Traps were placed in the orchard during the morning and removed for fly counts the following morning. Positions of the 2 treatments within blocks were alternated between the 2 test trees for each replication over time. Sugar-fed, protein-starved flies that had been irradiated as described above (irradiation experiment) were released into the test orchard when 2-10 d old during the late afternoon of the day before a test. Approximately 2,000 flies were distributed equally in the 6 blocks.

One replication of the experiment over time consisted of 6 tests of each lure ( 1 of each lure in each block). Twenty replications over time were conducted for a total of 120 traps with each lure. Replications over time and space were treated as equivalent for statistical analyses.

Statistical Analyses. Effects of hunger status, irradiation, sex, lure type, and various factor interactions on responses of flies in the wind-tunnel bioassay were tested by chi-square using the log linear model procedure of SYSTAT 7.0 (SYSTAT 1997). The effect of fly age on response was tested in the irradiation experiment using option Cochran (Cochran's test of linear trend) of the XTAB procedure of SYSTAT 7.0.

Graphical examination of responses to lures at different times of the day suggested 2nd order effects that differed by sex. Analysis of contingency tables could not be used to test these effects. Therefore, the effects of time of day on propensities of flies to contact the panels were tested by analyses of variance (ANOVA) of the combined data from the irradiation experiment and the sugar/protein deprivation experiment. For these analyses, proportions of flies to contact panels at each of 4 different times of the day were calculated from response frequencies within each treatment group in the 2 experiments. For example, the proportion of contacts by sugar-starved, protein-starved females to AMPu during the period from 0800 to 1000 hours was calculated as 0.56 ( 5 contacts out of 9 tests). This was done for each of the 4 treatment groups in the irradiation experiment and the 8 groups in the sugar/ protein deprivation experiment. The proportions calculated from the 12 groups at a given time of day were treated as 12 replicates, ignoring the fact that each was calculated from a different set of treatment factors such as hunger status, lure type, and so on. The proportions were transformed by arcsine of the square root (Snedecor and Cochran 1967). Proportions of 0 were replaced with $1 / 4 n$ and proportions of 1 were replaced with $(n-1 / 4) / n$. ANOVAs were conducted to calculate effects of time of day on responses of males and females and to calculate various sex by time of day interaction terms (Abacus Concepts 1989). These terms were used to test null hypotheses that time of day did not affect responses of either sex and that the sexes responded maximally at the same time of the day. 
Table 1. Effect of hunger status of Mexican fruit flies on number of flies to move upwind toward or contact yellow panels without lures in a wind tunne

\begin{tabular}{llcc}
\hline \hline \multicolumn{1}{c}{ Treatment } & & $\begin{array}{c}\text { Upwind } \\
\text { Movement }\end{array}$ & $\begin{array}{c}\text { Contact } \\
\text { with Panel }\end{array}$ \\
\hline Sugar fed/protein fed & Males & 10.0 & 0.0 \\
& Females & 5.0 & 0.0 \\
Sugar fed/protein starved & Males & 12.5 & 0.0 \\
& Females & 2.5 & 0.0 \\
Sugar starved/protein fed & Males & 7.5 & 2.5 \\
& Females & 5.0 & 0.0 \\
Sugar starved/protein starved & Males & 7.5 & 0.0 \\
& Females & 5.0 & 2.5 \\
\hline
\end{tabular}

Values are percentages of 40 flies in each cell.

The citrus orchard experiment was analyzed by 1-way ANOVA of trap captures. Means separations were done by the Fisher protected least significant difference (LSD) method.

\section{Results}

Sugar/Protein Deprivation Experiment. Sugar/ protein deprivation treatment groups did not differ from each other in propensity to move upwind and contact panels without lures (Table 1). Thus, it was assumed that differences in general activity levels of the groups did not affect their responses to the lures in the following analysis.

In wind-tunnel bioassays with lures (Table 2), sugar/protein deprivation effects were not significant in the overall model that included the 4 sugar/protein deprivation treatments, sex, and lure type. Significantly more females than males moved upwind $\left(\chi^{2}=\right.$ $18.5, \mathrm{df}=1, P<0.001)$ and contacted $\left(\chi^{2}=19.6, \mathrm{df}=\right.$ $1, P<0.001)$ panels with lures. Significantly more flies moved upwind $\left(\chi^{2}=12.4\right.$, df $\left.=1, P<0.001\right)$ and contacted $\left(\chi^{2}=20.4, \mathrm{df}=1, P<0.001\right)$ panels with AMPu than panels with BioLure. No interactions among the variables hunger, sex, and lure type were significant in the overall model.

In statistical analyses of reduced models, sugar/ protein deprivation affected responses of flies to the lures. Sugar-fed, protein-starved flies generally were
Table 3. Effect of gamma irradiation of Mexican fruit flies on propensity of flies to move upwind toward or contact synthetic lures in a wind tunnel

\begin{tabular}{|c|c|c|c|c|}
\hline & \multicolumn{2}{|c|}{ Upwind Movement } & \multicolumn{2}{|c|}{ Contact with Source } \\
\hline & BioLure & AMPu & BioLure & $\mathrm{AMPu}$ \\
\hline \multicolumn{5}{|c|}{ Not irradiated } \\
\hline Males & 22.5 & 40.0 & 10.0 & 32.5 \\
\hline Females & 40.0 & 62.5 & 25.0 & 50.0 \\
\hline \multicolumn{5}{|c|}{ Gamma irradiated } \\
\hline Males & 22.5 & 25.0 & 2.5 & 17.5 \\
\hline Females & 25.0 & 32.5 & 12.5 & 25.0 \\
\hline
\end{tabular}

Values are percentages of 40 flies in each cell.

more responsive to both lures than were other treatment groups. Summed over both lures, sugar-fed, protein-starved females contacted panels at significantly higher rates than did other groups of females $\left(\chi^{2}=4.6\right.$, $\mathrm{df}=1, P<0.05)$. Upwind movement was not significantly different and the effect on contacts with panels was not significant for each lure separately. Sugar-fed females flew upwind and contacted panels with lures more often than did sugar-starved females, although the effect was not significant at the $5 \%$ level. The effect was nearly significant for contact with panels with $\operatorname{AMPu}\left(\chi^{2}=3.5, \mathrm{df}=1, P=0.06\right)$. Sugar-starved, protein-starved females contacted panels with AMPu lures significantly less than did other groups of females $\left(\chi^{2}=4.7, \mathrm{df}=1, P<0.05\right)$.

Protein deprivation effects were evident for response to BioLure. Protein-starved flies generally flew upwind and contacted panels with BioLure more frequently than did protein-fed flies. The effect was significant for contacts by males $\left(\chi^{2}=5.5\right.$, df $=1, P<$ $0.05)$. Protein deprivation effects were not significant for response to panels with AMPu.

Irradiation Experiment. Significantly fewer irradiated flies compared with nonirradiated flies moved upwind $\left(\chi^{2}=7.8, \mathrm{df}=1, P<0.01\right)$ and contacted $\left(\chi^{2}\right.$ $=8.1, \mathrm{df}=1, P<0.01$ ) panels with lures (Table 3 ). Significantly more females than males moved upwind $\left(\chi^{2}=5.3, \mathrm{df}=1, P<0.05\right)$ and contacted $\left(\chi^{2}=5.4\right.$, $\mathrm{df}=1, P<0.05)$ the panels. Significantly more flies moved upwind $\left(\chi^{2}=5.3\right.$, df $\left.=1, P<0.05\right)$ and contacted $\left(\chi^{2}=12.0, \mathrm{df}=1, P<0.001\right)$ panels with

Table 2. Effect of hunger status of Mexican fruit flies on number of flies to move upwind toward or contact synthetic lures in a wind tunnel

\begin{tabular}{|c|c|c|c|c|c|}
\hline Sugar fed/protein fed & $\begin{array}{l}\text { Males } \\
\text { Females }\end{array}$ & $\begin{array}{l}18.3 \\
31.7\end{array}$ & $\begin{array}{l}31.7 \\
50.0\end{array}$ & $\begin{array}{r}3.3 \\
20.0\end{array}$ & $\begin{array}{l}20.0 \\
41.7\end{array}$ \\
\hline Sugar fed/protein starved & $\begin{array}{l}\text { Males } \\
\text { Females }\end{array}$ & $\begin{array}{l}18.3 \\
41.7\end{array}$ & $\begin{array}{l}30.0 \\
48.3\end{array}$ & $\begin{array}{l}10.0 \\
30.0\end{array}$ & $\begin{array}{l}25.0 \\
43.3\end{array}$ \\
\hline Sugar starved protein starved & $\begin{array}{l}\text { Males } \\
\text { Females }\end{array}$ & $\begin{array}{l}26.7 \\
28.3\end{array}$ & $\begin{array}{l}35.0 \\
38.3\end{array}$ & $\begin{array}{l}15.0 \\
18.3\end{array}$ & $\begin{array}{l}23.3 \\
25.0\end{array}$ \\
\hline
\end{tabular}

Values are percentages of 60 flies in each cell. 


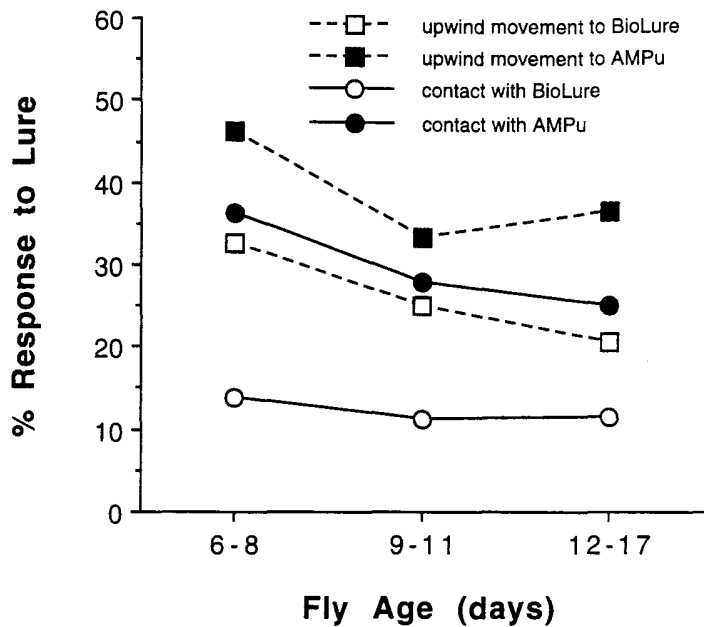

Fig. 1. Attraction of Mexican fruit flies to lures in a wind tunnel as a function of fly age. $n: 6-8 \mathrm{~d}, 80$ tests per lure; $9-11$ d, 36; 12-17 d, 44 .

AMPu than panels with BioLure. Effects of irradiation and sex on response to both lures were the same; i.e., no interactions of irradiation or sex with each other or with lure type were significant.

Effect of Fly Age. Response rates of flies 6-8 d after eclosion were numerically higher than those of older flies in the irradiation experiment (Fig. 1). Because interactions of factors were not significant in the analysis above, data were pooled for irradiation, sex, and lure type for the purpose of analysis of effect of fly age. Cochran's tests of linear trend for upwind movement versus fly age $\left(\chi^{2}=3.4, \mathrm{df}=1, P=0.06\right)$ and contact with the panels versus fly age $\left(\chi^{2}=1.7, \mathrm{df}=1, P=\right.$ $0.19)$ were not significant at the $5 \%$ level.

Effect of Time of Day. Fig. 2 shows that maximal responses by females occurred early and late in the photophase whereas male responses were lowest late in the photophase and highest during midphotophase. ANOVA of the combined data from the irradiation experiment and the sugar/protein deprivation experiment showed that the interaction of sex by time of day was significant $(F=3.5 ; \mathrm{df}=3,77 ; P<0.05)$, indicating that responses of sexes were not uniform over the day. Because visual examination of Fig. 2 suggested quadratic effects for both males and females, an analysis of the quadratic component of the sex by time of day interaction was conducted. The quadratic regression sum of squares for a model that did not contain sex as a factor (data from males and females pooled) was calculated as 210.8 by quadratic contrast. This regression was not significant $(F=1.5 ; \mathrm{df}=1,81 ; P=0.22$ ) because the quadratic effects of males and females cancel each other. Quadratic regression sums of squares were similarly calculated for models containing only data for males ( $\mathrm{SS}=78.1 ; F=1.1 ; \mathrm{df}=1,33$; $P=0.30$ ) or females ( $\mathrm{SS}=862.5 ; F=7.6 ; \mathrm{df}=1,33$; $P<0.01$ ). The analyses indicated that female responding was significantly greater early and late in the photophase than during midphotophase, but responding

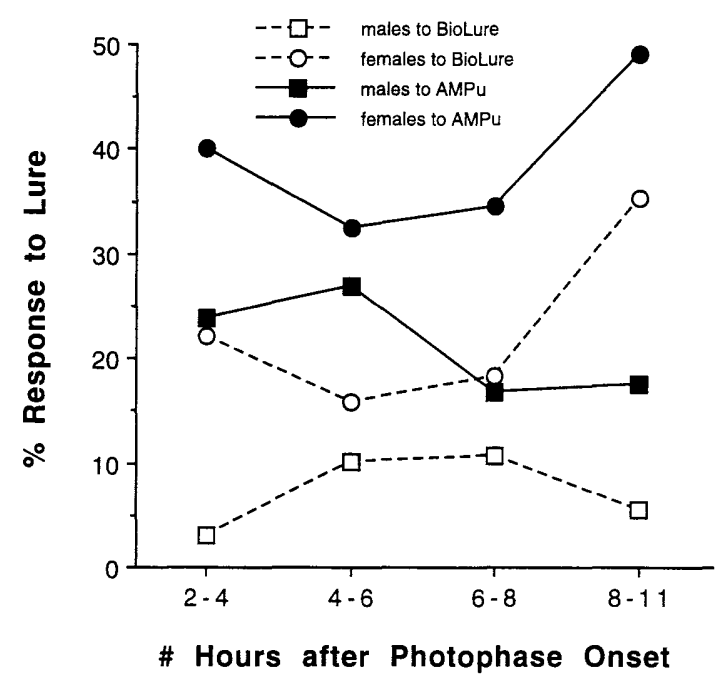

Fig. 2. Attraction of Mexican fruit flies to lures in a wind tunnel as a function of time of day. Each data point is the mean percentage of 6 replications, where each replication is the percentage of flies to respond within a treatment group.

by males did not differ significantly with time of day. The overall quadratic sum of squares (210.8) was subtracted from the combined sums of squares from males and females analyzed separately $(78.1+862.5)$ to obtain the sex by time of day quadratic interaction sum of squares (729.7). This interaction was significant $(F=7.9 ; \mathrm{df}=1,77 ; P<0.01)$, indicating that males and females responded to the lures maximally at different times of the day.

Citrus Orchard Test. Traps baited with AMPu captured $\approx 2.5$ times more irradiated male and female Mexican fruit flies than traps baited with BioLure (Fig. $3)$. Results were significant for both males $(F=12.3$; $\mathrm{df}=1,238 ; P<0.001)$ and females $(F=14.1 ; \mathrm{df}=1$, 238; $P<0.001$ ).

\section{Discussion}

Effects of food deprivation were considerably smaller than expected. Robacker and Garcia (1993) demonstrated that attraction of Mexican fruit flies to bacterial odor (Staphylococcus) was greatly depressed if flies were sugar-starved. These authors and Robacker and Moreno (1995) also showed that attraction to Staphylococcus odor was greatly enhanced if flies were protein-starved. As pointed out above (Materials and Methods), Staphylococcus odor emits many of the same chemicals as AMPu and BioLure. In the current work, sugar deprivation had only a slight depressant effect on attraction to the lures and protein deprivation had a slight activation effect, but only for attraction to BioLure.

Effects of hunger on attraction of other species of Tephritidae to food-based olfactory attractants have not been well documented. Liu and Chang (1995) showed that protein-deprivation increased attraction 


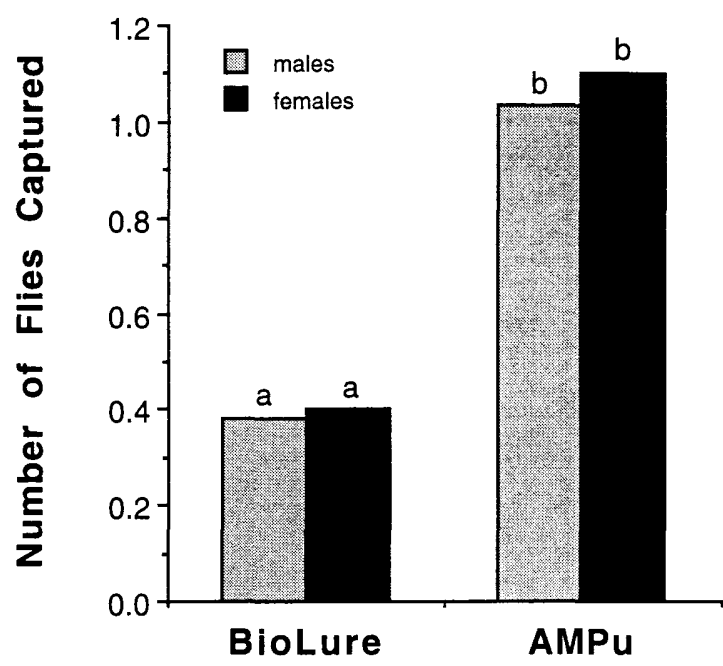

Fig. 3. Mean number of gamma-irradiated Mexican fruit flies captured by traps baited with synthetic lures in a citrus orchard. $n=120$ traps per lure.

of melon flies (Bactrocera cucurbitae Coquillett) to a proteinaceous attractant. Prokopy et al. (1996) obtained similar results with Mediterranean fruit fly attraction to a standard proteinaceous bait and to $\mathrm{Bi}$ oLure. Prokopy et al. (1998) also demonstrated that protein feeding increased attraction of female Mediterranean fruit flies to odor of coffee berries, a natural oviposition host of this species, suggesting that the response was for oviposition rather than feeding. This finding suggests potential for much new research on ovipositional attractants in fruit flies.

Effects of gamma irradiation were expected. Robacker and Garcia (1993) observed an $\approx 20 \%$ reduction in attraction to bacterial odor by irradiated flies compared with nonirradiated flies. Galun et al. (1985) showed that gamma irradiation of Mediterranean and Caribbean fruit flies, Anestrepha suspensa (Loew), decreased the olfactory response of the flies to protein hydrolysate by about the same percentage as observed here for Mexican fruit fly response to AMPu and BioLure. Heath et al. (1996) suggested that ammonium acetate/putrescine lures (BioLure) were much more attractive to wild Mediterranean fruit flies than to irradiated laboratory-colony flies based on captures in field tests; however, it was not possible to make an accurate assessment because of unknown population sizes of wild versus irradiated flies.

Effects of sex also were expected. More females than males have been captured by both AMPu and BioLure in field tests (Heath et al. 1995, 1996; Robacker 1995). As discussed above, it is difficult to assess relative attractiveness to females and males in field tests because of unknown sizes of responding populations of the 2 sexes.

Although fly age did not significantly affect attraction of flies to the 2 lures in the current work, the trend was toward lower responsiveness of flies as they aged beyond $8 \mathrm{~d}$ after eclosion (Fig. 1). The same effect was observed for attraction of Mexican fruit flies to bacterial odor in laboratory experiments (Robacker and Garcia 1993).

Robacker and Garcia (1993) reported that bacterial odor was most attractive to Mexican fruit flies during midphotophase from $2 \mathrm{~h}$ after photophase onset until $3 \mathrm{~h}$ before scotophase onset. Responses of males and females were not separated in that study. The current work shows that males and females respond maximally at different times of the day both to AMPu and BioLure. Unfortunately, observations very early or very late in the photophase were not included in the current work. An experiment designed specifically to determine effects of time of day on attraction to these types of lures is needed.

$\mathrm{AMPu}$ was consistently more attractive than BioLure to Mexican fruit flies both in wind-tunnel bioassays and in the citrus orchard test. Although the 2 lures were tested at only 1 emission rate each in these experiments, AMPu was tested as the formulation that had been proven most attractive in field tests (Robacker 1995) and BioLure was tested as recommended by the manufacturer for field trapping. It is possible that emission rates of BioLure components may not be optimal for maximum attractiveness in wind-tunnel bioassays. However, AMPu was also more attractive than BioLure in 1-d citrus orchard tests. Obviously, a long-lasting formulation would be needed before AMPu could be considered as a viable commercial lure.

The relative attraction to $\mathrm{AMPu}$ versus BioLure varied from $\approx 1.4$ for sugar-starved, protein-starved females to 7.0 for gamma-irradiated males. Such great differences in relative attractiveness indicate that physiological state affects attraction of flies to these 2 lures differently, as was postulated in the introduction. This suggests that the 2 lures may differ in efficacy in the field, depending on local conditions that affect the physiological state of the target populations.

Food availability is 1 example of how local conditions may affect physiological states of populations. Fruit flies need carbohydrate on almost a daily basis to supply energy and protein during sexual maturation and for life-long fecundity (Chippendale 1978, Prokopy and Roitberg 1984, Fletcher 1987, Tsitsipis 1989). Typical carbohydrate sources of fruit flies include fruit juices, plant exudates and honeydews; protein sources include pollens, honeydews, microorganisms, and bird feces (Baker et al. 1944, Fletcher 1987, Aluja 1994). Flies inhabiting orchards that contain little fruit fly food may be both sugar and protein hungry. Data in Table 2 indicate that AMPu and BioLure should be similar in attractiveness in this setting. Flies in orchards full of ripe and rotting fruit and associated microorganisms and feces from frugivorous birds may be both sugar and protein satiated. Flies in this setting should find AMPu more attractive than BioLure according to data in Table 2.

In addition, other factors may affect relative attractiveness of various lures. These include genetic differences between populations of flies from different 
localities or between laboratory-colony and wild flies, and climatic differences.

\section{Acknowledgments}

I thank Maura Rodriguez and Connie Chavez for technical assistance, USDA-APHIS (Mission, TX) for irradiation of pupae, and Bob Heath (USDA-ARS, Gainesville, FL) and Peter Landolt (USDA-ARS, Wapato, WA) for the wind tunnels. Thanks are also extended to Peter Landolt, John Worley (USDA-APHIS, Mission, TX), and Nancy Epsky (USDAARS, Gainesville, FL) for critical reviews of the manuscript.

\section{References Cited}

Abacus Concepts. 1989. SuperANOVA. Abacus Concepts, Berkeley, CA.

Aluja, M. 1994. Bionomics and management of Anastrepha. Annu. Rev. Entomol. 39: 155-178.

Baker, A. C., W. E. Stone, C. C. Plummer, and M. McPhail, 1944. A review of studies on the Mexican fruitfly and related Mexican species. U.S. Dep. Agric. Misc. Publ. 531.

Chippendale, G. M. 1978. The functions of carbohydrates in insect life processes, pp. 1-55. In M. Rockstein [ed.], Biochemistry of insects. Academic, New York.

Epsky, N. D., B. D. Dueben, R. R. Heath, C. R. Lauzon, and R. J. Prokopy. 1997. Attraction of Anastrepha suspensa (Diptera: Tephritidae) to volatiles from avian fecal material. Fla. Entomol. 80: 270-277.

Fletcher, B. S. 1987. The biology of the dacine fruit flies. Annu. Rev. Entomol. 32: 115-144.

Galun, R., S. Gothilf, S. Blondheim, J. L. Sharp, M. Mazor, and A. Lachman. 1985. Comparison of aggregation and feeding responses by normal and irradiated fruit flies, Ceratitis capitata and Anastrepha suspensa (Diptera: Tephritidae). Environ. Entomol. 14: 726-732.

Heath, R. R., N. D. Epsky, B. D. Dueben, and W. L. Meyer. 1996. Systems to monitor and suppress Ceratitis capitata (Diptera: Tephritidae) populations. Fla. Entomol. 79: 144-153.

Heath, R. R., N. D. Epsky, B. D. Dueben, J. Rizzo, and F. Jeronimo. 1997. Adding methyl-substituted ammonia derivatives to a food-based synthetic attractant on capture of the Mediterranean and Mexican fruit flies (Diptera: Tephritidae). J. Econ. Entomol. 90: 1584-1589.

Heath, R. R., N. D. Epsky, A. Guzman, B. D. Dueben, A. Manukian, and W. L. Meyer. 1995. Development of a "dry" plastic trap with food-based synthetic attractant for the Mediterranean and Mexican fruit flies (Diptera: Tephritidae). J. Econ. Entomol. 88: 1307-1315.

Landolt, P. J., R. R. Heath, and D. L. Chambers. 1992. Oriented flight responses of female Mediterranean fruit flies to calling males, odor of calling males, and a synthetic pheromone blend. Entomol. Exp. Appl. 65: 259-266.
Liu, Y. C., and C. T. Chang. 1995. Attraction of food attractants to melon fly, Dacus cucurbitae Coquillett. Chin. J. Entomol. 15: 69-80.

Prokopy, R. J., and B. D. Roitberg. 1984. Foraging behavior of true fruit flies. Am. Sci. 72: $41-49$

Prokopy, R. J., X. Hu, E. B. Jang, R. I. Vargas, and J. D. Warthen. 1998. Attraction of mature Ceratitis capitata females to 2-heptanone, a component of coffee fruit odor. J. Chem. Ecol. 24: 129:3-1304.

Prokopy, R. J., S. S. Resilva, and R. I. Vargas. 1996. Postalighting behavior of Ceratitis capitata (Diptera: Tephritidae) on odor-baited traps. Fla. Entomol. 79: 422-428.

Robacker, D. C. 1992. Effects of shape and size of colored traps on attractiveness to irradiated, laboratory-strain Mexican fruit flies (Diptera: Tephritidae). Fla. Entomol. 75: $230-241$

1995. Attractiveness of a mixture of ammonia, methylamine and putrescine to Mexican fruit flies (Diptera: Tephritidae) in a citrus orchard. Fla. Entomol. 78: 571578.

Robacker, D. C., and R. J. Bartelt. 1996. Solid-phase microextraction analysis of static-air emissions of ammonia, methylamine, and putrescine from a lure for the Mexican fruit fly (Anastrepha ludens). J. Agric. Food Chem. 44: $3554-3559$

Robacker, D. C., and R. A. Flath. 1995. Attractants from Staphylococcus aureus cultures for Mexican fruit fly, Anastrepha ludens. J. Chem. Ecol. 21: 1861-1874.

Robacker, D. C., and J. A. Garcia. 1993. Effects of age, time of day, feeding history, and gamma irradiation on attraction of Mexican fruit flies (Diptera: Tephritidae) to bacterial odor in laboratory experiments. Environ. Entomol. 22: 1367-1374.

Robacker, D. C., and D. S. Moreno. 1995. Protein feeding attenuates attraction of Mexican fruit flies (Diptera: Tephritidae) to volatile bacterial metabolites. Fla. Entomol. 78: 62-69.

Robacker, D. C., and W. C. Warfield. 1993. Attraction of both sexes of Mexican fruit fly, Anastrepha ludens, to a mixture of ammonia, methylamine, and putrescine J. Chem. Ecol. 19: 2999-3016.

Robacker, D. C., D. S. Moreno, and A. B. DeMilo. 1996. Attractiveness to Mexican fruit flies of combinations of acetic acid with ammonium/amino attractants with emphasis on effects of hunger. J. Chem. Ecol. 22: 499-511.

Snedecor, G. W., and W. G. Cochran. 1967. Statistical methods. Iowa State University Press, Ames.

SYSTAT. 1997. SYSTAT 7.0. SPSS, Chicago, IL.

Tsitsipis, J. A. 1989. . Nutrition, pp. 103-109. In A. S. Robinson and G. Hooper [ed.], Fruit flies: their biology, natural enemies and control, vol.3A. Elsevier, New York.

Received for publication 18 March 1998; accepted 25 August 1998. 